\title{
Pedagogia da segurança laboratorial - solventes no ensino secundário
}

\author{
J. Ricardo M. Pinto, ${ }^{a}$ M. Gabriela T. C. Ribeiro, ${ }^{a, *}$ Adélio A. S. C. Machado ${ }^{b}$ \\ ${ }^{\text {a }}$ LAQV/REQUIMTE, Departamento de Química e Bioquímica, Faculdade de Ciências da Universidade do Porto, Rua do Campo Alegre 687, \\ Porto 4169-007, Portugal \\ b Departamento de Química e Bioquímica, Faculdade de Ciências da Universidade do Porto, Rua do Campo Alegre 687, Porto 4169-007, Portugal \\ *gribeiro@fc.up.pt
}

\begin{abstract}
Laboratory safety pedagogy - solvents in secondary schools - The safety of the solvents proposed for the laboratory experiments prescribed by the chemistry programs for the secondary education in Portugal was assessed by two procedures: solvent selection guides published by pharmaceutical companies and a new graphic tool for presentation of the hazards of chemical substances presented here. This SHE tool collects data on the three types of hazards (SHE hazards: Physical Safety, Human Health and Environment) from Safety Data Sheets (SDS) for substances and presents them in an easily read graphic shape allowing a global vision of hazards. The comparison of the results of the two assessments shows discrepancies, attributed to the difficulties of evaluating chemical safety due to the complexities of the chemistry and of the hazards of substances themselves. The study showed that the programs and corresponding textbooks prescribe a set of solvents that include a number of dangerous or very dangerous solvents, their replacement being advisable. Further limitations of the programs on laboratory safety are discussed, suggesting a reshaping of safety teaching to promote safety culture.
\end{abstract}

A presenta-se uma análise da segurança dos solventes propostos nas experiências prescritas pelos programas de química do Ensino Secundário, realizada por dois processos: utilização de guias de segurança de solventes publicados por empresas farmacêuticas e uma ferramenta de apresentação gráfica dos perigos das substâncias químicas cuja conceção original se descreve. Esta última, chamada ferramenta SHE, usa as fichas de dados de segurança de produtos químicos (SDS) para recolher informação sobres os seus perigos de segurança física (Safety), para a saúde humana (Human Health) e para o ambiente (Environment), que apresenta em forma gráfica de apreensão visual fácil e imediata. A comparação dos resultados dos dois tipos de análise mostra discrepâncias, esperadas em face das dificuldades de avaliação da segurança química, consequência das complexidades da química e dos próprios perigos das substâncias. O estudo revelou que o programa e manuais escolares prescrevem solventes de que uma parte substancial são perigosos ou muito perigosos, aconselhando-se a sua substituição. Apontam-se outras limitações dos programas quanto a segurança laboratorial e necessidade de reformatar o ensino desta para promover uma verdadeira cultura de segurança.

\section{Introdução}

Nos anos sessenta do século XX, tomou-se consciência de que a atividade da Química Industrial na produção de produtos químicos em larga escala, a par da demais atividade industrial, da produção de energia elétrica e dos transportes, contribuía para a dispersão intensa de poluentes e a produção de grandes quantidades de resíduos, provocando fortes impactos negativos no ambiente e na saúde humana e ecológica. Reconhecida esta situação, e sendo a atividade da Indústria Química essencial para a civilização industrial, surgiu a necessidade de tomar providências para compatibilizar a prática da química com a proteção do ambiente. Neste âmbito, foi implementada uma sucessão de medidas reativas aplicadas a posteriori aos processos químico-industriais vigentes, sem grande sucesso na correção dos referidos impactos. Nos anos noventa acabou por emergir a Química Verde (QV), uma proposta de prática inovadora da química, em particular da Química Industrial, com o objetivo de obter proteção intencional do ambiente $a$ priori por design de produtos e processos ambientalmente inócuos [1,2]. Os objetivos globais da QV foram explicitados por Anastas e Warner [2] cujos doze princípios constituem um guia para o desenvolvimento de produtos mais benignos, conceção de processos mais limpos, substituição de produtos com elevada perigosidade para a saúde humana e ambiente por outros menos perigosos, etc. Como os objetivos da QV são multidimensionais, a sua implementação tem sido prosseguida por variadas linhas, sendo a substituição de substâncias perigosas por outras com menores riscos uma das mais praticadas, embora limitada e nem sempre exequível, devido fundamentalmente à complexidade dos perigos potenciais das substâncias químicas [3].

Estes perigos são variados, sendo classificados em três tipos: perigos físicos, referentes à segurança física (incêndio, explosão, etc.); perigos para a saúde humana (corrosão de tecidos e órgãos, intoxicações de variados tipos, etc.); e perigos para o ambiente (também de variados tipos, desde ecotoxicidade variada, até perigos de natureza global, p. ex., a depleção da camada de ozono estratosférico ou a contaminação atmosférica por compostos que intensificam o efeito de estufa). Os perigos potenciais das substâncias químicas são vulgarmente designados por "perigos SHE", recorrendo à abreviatura do inglês: Safety, Human Health and Environment. Para prevenir confusões, note-se que nesta abreviatura a palavra segurança do $\mathrm{S}$ se refere apenas aos perigos físicos, tendo um alcance mais restrito do que no uso genérico que vulgarmente lhe é atribuído. A QV permite diversas estratégias para eliminar proativamente os perigos SHE [4]. 
Neste contexto, a minimização do uso de solventes perigosos tem merecido muito interesse [5]. Na atividade industrial, a indústria farmacêutica tem dado atenção prioritária à utilização de solventes mais verdes para obter sínteses mais sustentáveis, o que foi motivado pelos grandes volumes de solventes que os processos de síntese de moléculas elaboradas requerem. Tal esforço foi impulsionado em 2005 pelo Instituto de Química Verde (GCI, Green Chemistry Institute) da Sociedade Americana de Química (ACS, American Chemical Society), que promoveu uma discussão continuada entre várias empresas farmacêuticas com vista a desenvolverem uma ação global para catalisar a introdução da QV nesta indústria [6], a qual levou ao estabelecimento da ACS Green Chemistry Pharmaceutical Roundtable (GCI-PR) [7]. Neste contexto, várias empresas deste grupo têm desenvolvido guias de seleção de solventes para ajudarem os seus químicos a privilegiarem o uso dos solventes mais verdes em substituição dos mais problemáticos [5].

O esforço de substituição de solventes tem também visado os laboratórios de ensino, nomeadamente no ensino superior, tendo surgido na literatura várias propostas de experiências de síntese alternativas às vigentes, sobre sínteses sem solventes [8-10] ou em meio aquoso [8,11]. Por exemplo, Dicks $[10,11]$ apresentou várias sínteses sem solventes, discutindo as suas vantagens [10]. Noutro trabalho destacou as vantagens da água como solvente relativamente aos solventes orgânicos [11]. Outros autores têm reportado experiências onde solventes tóxicos e perigosos são substituídos por outros mais benignos, de modo a conseguir processos de síntese mais verdes [12-15]. No entanto, a análise sistemática do uso corrente de solventes nos laboratórios de ensino com vista a aumentar a segurança não parece ter merecido ainda atenção, apesar dos numerosos acidentes ocorridos em laboratórios e em demonstrações, resultantes dos seus variados perigos, por exemplo, com metanol [16], e da recente mudança de atitude perante a perigosidade química, no sentido de promover mais incisivamente o ensino da segurança química com vista a incutir nos estudantes uma cultura de segurança [17-18]. Em particular, o currículo de Química do Ensino Secundário em vigor no nosso país contém sugestões de atividades laboratoriais que envolvem o manuseamento e utilização de solventes com segurança problemática, o que nos mereceu o seu escrutínio.

Este artigo tem como objetivo último incentivar a substituição ou eliminação de solventes que envolvam perigos elevados no ensino da química, no quadro do desenvolvimento de uma nova pedagogia da segurança baseada na QV. Os seus objetivos próximos são dois: primeiro, fazer um levantamento dos perigos associados aos solventes usados atualmente no Ensino Secundário nacional para pressionar a erradicação dos que são perigosos; segundo, consciencializar os docentes quer para a necessidade de fazer sentir aos estudantes a importância dos perigos das substâncias químicas, quer para as dificuldades que a análise dessa perigosidade envolve, já que os diferentes processos de avaliação disponíveis conduzem frequentemente a resultados discrepantes.

Para cumprir estes objetivos, começou-se por identificar nos programas do Ensino Secundário as atividades la- boratoriais que envolviam solventes e consultar os correspondentes manuais para obter informação sobre os modos como eram usados. Esta consulta mostrou que eram propostos solventes alternativos aos indicados nos programas para a implementação das atividades, mas sem explicações para as mudanças. Procedeu-se depois à análise da perigosidade com dois tipos de instrumentos: guias de solventes, em especial o da GSK [19] (ver adiante), e uma ferramenta de prospeção dos perigos das substâncias químicas desenvolvida anteriormente no grupo [20] e agora melhorada, a ferramenta SHE, concebida para utilização em contexto escolar. Em seguida analisaram-se comparativamente os resultados obtidos para as diversas ferramentas, com vista a evidenciar as suas discrepâncias e definir as vantagens e desvantagens de cada uma delas e a respetiva utilidade. Finalmente, examinaram-se as implicações do estudo realizado quanto à utilização dos solventes e outros aspetos de segurança no Ensino Secundário. As secções seguintes reportam sucessivamente estas tarefas.

\section{Solventes propostos para o ensino secundário}

Na Tabela 1 apresenta-se a lista de solventes propostos nas atividades laboratoriais no Ensino Secundário, com indicação da origem da respetiva menção (programas para o Ensino Secundário e/ou manuais escolares) [21-29]. Os solventes incluídos neste estudo são os compostos inseridos nos guias de solventes devido ao seu uso vulgar em química nessa função, embora nem sempre sejam usados nas atividades como solventes, mas sim como reagentes, componentes de mistura a destilar, etc.

\section{Guias de seleção de solventes}

Nos guias de solventes elaborados por empresas (AstraZeneca [30], Pfizer [31], GlaxoSmithKline (GSK) [19, 32-34] e Sanofi [35]) cada uma aplica uma estratégia própria de avaliação da perigosidade dos solventes usados nas suas operações. A estratégia é condicionada pela atividade industrial desenvolvida pela empresa e o seu passado histórico, sendo os guias elaborados de modo a obter uma avaliação hierárquica da segurança dos solventes usados, com vista a promover o uso de solventes de menor perigosidade. Para cumprir esta finalidade os guias permitem: (i) escolher solventes com perfil mais sustentável para novas sínteses; (ii) substituir solventes em uso por outros mais benignos.

O modo de estabelecimento dos guias raramente é detalhado no material publicado e nem sempre se procura obter uma hierarquização individualizada dos solventes quanto à respetiva segurança que defina inequivocamente uma ordem de preferência de utilização. Em vez disto, o tratamento de um conjunto de informações numerosas e variadas conduz, geralmente, a uma classificação dos solventes em três níveis, na forma de "sinais de trânsito": verde: solvente benigno, a manter; amarelo (ou âmbar): aceitável; e vermelho: perigoso, a substituir (as designações dos níveis variam com o guia, sendo de notar também que um dos guias usa uma classificação com quatro níveis [32]). A classificação verde-amarelo/âmbar-vermelho tem a vantagem de ser fácil de manejar, permitindo a evolução para o uso de solventes mais benignos quando surgem oportunidades para isso, sem pôr em causa a atividade industrial. 
Tabela 1 - Solventes utilizados nas atividades laboratoriais do Ensino Secundário.

\begin{tabular}{|c|c|c|}
\hline Solvente & Atividade laboratorial & Origem \\
\hline Acetona & AL 2.1. Miscibilidade de líquidos & $\begin{array}{l}\text { Programa 10. ano [21] } \\
\text { Manual “Química } 10 \text { A” [22] } \\
\text { Manual “Química 10” [23] } \\
\text { Manual “Eu e a Química 10” [24] } \\
\text { Manual “Há Química entre nós” [25] } \\
\text { Manual “Novo 10Q” [26] } \\
\text { Manual “Química entre nós” [27] }\end{array}$ \\
\hline Butan-1-ol & $\begin{array}{l}\text { AL 2.5. Determinação da entalpia de } \\
\text { combustão de diferentes álcoois }\end{array}$ & Programa $12 .^{\circ}$ ano [28] \\
\hline Diclorometano & AL 2.1. Miscibilidade de líquidos & Manual “Química 10” [23] \\
\hline Etanol & $\begin{array}{l}\text { AL 2.1. Miscibilidade de líquidos } \\
\text { AL 2.5. Determinação da entalpia de } \\
\text { combustão de diferentes álcoois }\end{array}$ & $\begin{array}{l}\text { Programa 10. a ano [21] } \\
\text { Manual “Química } 10 \text { A” [22] } \\
\text { Manual “Química 10” [23] } \\
\text { Manual “Eu e a Química 10” [24] } \\
\text { Manual “Há Química entre nós, 10. ano” [25] } \\
\text { Manual “Novo 10Q” [26] } \\
\text { Manual “Novo Jogo de partículas” [29] } \\
\text { Programa 12. ano [28] } \\
\text { Manual “Química entre nós” [27] }\end{array}$ \\
\hline Éter de petróleo & AL 2.1. Miscibilidade de líquidos & $\begin{array}{l}\text { Programa } 10 \text { o ano [21] } \\
\text { Manual "Há Química entre nós” [25] }\end{array}$ \\
\hline Éter dietílico & AL 2.1. Miscibilidade de líquidos & Manual “Química entre nós” [27] \\
\hline Hexano & AL 2.1. Miscibilidade de líquidos & $\begin{array}{l}\text { Programa 10. ano [21] } \\
\text { Manual “Química } 10 \text { A” [22] } \\
\text { Manual “Química 10” [23] } \\
\text { Manual “Eu e a Química 10” [24] } \\
\text { Manual “Há Química entre nós” [25] } \\
\text { Manual “Novo 10Q” [26] } \\
\text { Manual “Novo Jogo de partículas” [29] } \\
\text { Manual “Química entre nós” [27] }\end{array}$ \\
\hline \multirow[t]{2}{*}{ Metanol } & $\begin{array}{l}\text { AL 2.1. Destilação fracionada de uma } \\
\text { mistura de três componentes } \\
\text { APL2 - Produção de um biodiesel a partir } \\
\text { de óleos alimentares } \\
\text { AL 2.5. Determinação da entalpia de } \\
\text { combustão de diferentes álcoois }\end{array}$ & Programa $12 .^{\circ}$ ano [28] \\
\hline & AL 1.2. Teste de chama & $\begin{array}{l}\text { Manual “Química 10” [23] } \\
\text { Manual “Eu e a Química 10” [24] } \\
\text { Manual “Há Química entre nós” [25] }\end{array}$ \\
\hline Pentano & AL 2.1. Miscibilidade de líquidos & Manual “Novo jogo de partículas” [29] \\
\hline Propan-1-ol & $\begin{array}{l}\text { AL 2.5. Determinação da entalpia de } \\
\text { combustão de diferentes álcoois }\end{array}$ & Programa $12 .^{\circ}$ ano [28] \\
\hline Propan-2-ol & $\begin{array}{l}\text { AL 2.5. Determinação da entalpia de } \\
\text { combustão de diferentes álcoois }\end{array}$ & Programa $12 .^{\circ}$ ano $[28]$ \\
\hline $\begin{array}{l}\text { Tetracloreto de } \\
\text { carbono }\end{array}$ & AL 3.6. Síntese de um polímero & Programa $12 .^{\circ}$ ano $[28]$ \\
\hline Xileno & AL 2.1. Miscibilidade de líquidos & Manual “Novo 10Q” [26] \\
\hline
\end{tabular}


Para se definir o nível de classificação, cada solvente é normalmente avaliado em diferentes categorias de perigos SHE (e, eventualmente, de informação doutros tipos, p. ex., regulamentações de substâncias perigosas, caraterísticas dos resíduos, avaliação do ciclo de vida, etc.), mediante escalas definidas com base em critérios específicos considerados adequados, que variam de guia para guia. $\mathrm{O}$ número de categorias usadas, o número de níveis de escala e o sentido desta (aumento com a perigosidade ou com a segurança, que são caraterísticas inversas) variam também de guia para guia (entre 3 e 14), tal como o número de solventes que os integram. Esta variedade de detalhes na avaliação dificulta ou impede a comparação de resultados e dá origem a confusões, o que levou a GCI-PR [7] a lançar a preparação de um guia por cooperação entre empresas participantes [36], tendo publicitado uma versão provisória em 2011 [37], mas sem grandes detalhes quanto à sua elaboração (aparentemente semelhante à do guia da GSK). Desde então, não foi publicada qualquer outra versão deste guia coletivo.

Mais recentemente, por iniciativa de uma outra parceria público-privada criada na Europa, a "Innovative Medicines Initiative (IMI)-CHEM21" [38], abrangendo, tal como a GCI-PR, empresas farmacêuticas e universidades, estabelecida para desenvolver metodologias químicas e bioquímicas sustentáveis, foi feita uma avaliação comparativa dos guias de solventes disponíveis [5]. O estudo envolveu 51 solventes, nem todos incluídos em todos os guias, mas só para 34 foi possível atribuir inequivocamente um nível e só para 20 destes 34 houve acordo total (ou quase) entre os guias quanto aos níveis das pontuações. Dos 17 solventes com situação equívoca, para 11 a dúvida foi entre recomendado/problemático e para os outros 6 entre problemático/perigoso. Estas discrepâncias resultam das diferentes estratégias de elaboração, critérios de pontuação e formatos dos guias, desenvolvidos em empresas com culturas/filosofias diferentes, etc., que reúnem nos guias conjuntos de numerosos dados disponíveis, de modo a permitir aos seus técnicos tomar decisões em face da natureza variada dos processos de fabrico; para já não falar da complexidade intrínseca dos numerosos perigos das substâncias químicas [3] e de os requisitos exigidos aos solventes, nas suas variadas utilizações, conflituarem frequentemente com es- tes perigos, o que exige compromissos. Esta complexidade composta por múltiplos componentes implica dificuldades variadas e revela a importância de se dispor de processos alternativos de análise da perigosidade dos solventes [39]. Na sequência desta comparação, a (IMI)-CHEM21 prosseguiu o seu trabalho com a elaboração de um guia próprio, o guia CHEM21 [40].

Quando os solventes listados na Tabela 1 foram avaliados por todos estes guias, confirmou-se que os resultados apresentavam numerosas discrepâncias [41]. Além disso, vários solventes da tabela não eram incluídos nos guias, o que limitava à partida a utilidade destes. A única exceção a esta incompletude foi o guia da GSK, que foi amadurecido em sucessivas revisões e na última [19] publicitou informação detalhada sobre a sua elaboração. Por isso, os respetivos resultados foram escolhidos para exemplificar o uso dos guias neste artigo, pelo que este guia será descrito brevemente a seguir.

\section{Guia de solventes da GSK}

O guia da GSK foi inicialmente publicado em 1999 com 35 solventes [32] e melhorado em 2004, com a introdução da avaliação dos respetivos ciclos de vida [33], e em 2011, com um aumento do número de solventes [34]. A versão atual (2016) [19] envolveu uma revisão completa e a atualização dos métodos de avaliação de perigos usados e proporciona abundante informação sobre eles, eliminando a falta de transparência sentida anteriormente nos outros guias; e inclui solventes adicionais, entre os quais alguns introduzidos nos últimos anos como sendo verdes, num total de 154 .

Cada área geral de avaliação envolve várias categorias (Tabela 2), pontuadas individualmente com base na combinação da avaliação de diversos aspetos, numa escala de 1 a 10, crescente com a segurança (e benignidade); por exemplo, no caso da "Inflamabilidade e Potencial de explosão” avaliam-se cinco aspetos: ponto de ebulição, ponto de inflamação, temperatura de autoignição, condutividade elétrica e pressão de vapor. A partir da pontuação das categorias individuais de cada área geral de avaliação, calcula-se a média geométrica como respetiva pontuação resumo (ver expressões na Tabela 2). As pontuações são usadas para atribuir cores aos solventes para cada categoria e cada área, segundo os critérios da Figura 1.

Tabela 2 - Áreas e categorias de avaliação e cálculos da pontuação resumo das áreas do guia da GSK [19].

\begin{tabular}{|c|c|c|}
\hline Área de avaliação & Categorias de avaliação & Cálculo da pontuação resumo da área \\
\hline \multirow{4}{*}{ Resíduos } & Incineração $(I)$ & \multirow{4}{*}{ Residuos $=\sqrt[4]{I \times R \times B T \times V O C}$} \\
\hline & Reciclagem $(R)$ & \\
\hline & Biotratamento $(B T)$ & \\
\hline & Emissões VOC (VOC) & \\
\hline \multirow{2}{*}{ Ambiente } & Impacto aquático $(A q)$ & \multirow{2}{*}{ Ambiente $=\sqrt{A q \times A r}$} \\
\hline & Impacto no ar $(A r)$ & \\
\hline \multirow{2}{*}{ Saúde humana } & Perigo para a saúde $(P)$ & \multirow{2}{*}{ Saủde Humana $=\sqrt{P \times E}$} \\
\hline & Potencial de exposição $(E)$ & \\
\hline \multirow[t]{2}{*}{ Segurança } & $\begin{array}{l}\text { Inflamabilidade e Potencial de ex- } \\
\text { plosão }(I \& E)\end{array}$ & \multirow[t]{2}{*}{ Segurança $=\sqrt{I \& E \times R \& E}$} \\
\hline & Reatividade e Estabilidade ( $R \& E$ ) & \\
\hline
\end{tabular}




\begin{tabular}{|c|c|}
\hline Código de cores & Intervalo da pontuação \\
\hline Verde & $p \geq 7,5$ \\
\hline Âmbar & $\mathbf{3 , 5} \leq \boldsymbol{p}<\mathbf{7 , 5}$ \\
\hline Vermelho & $p \leq \mathbf{3 , 5}$ \\
\hline
\end{tabular}

Figura 1 - Código de cores para a pontuação de cada categoria e critério para atribuição da pontuação resumo de cada área de avaliação (saúde, segurança, ambiente e resíduos) [19].

As pontuações das áreas são depois combinadas para calcular uma pontuação global única para cada solvente pontuação compósita. Esta pontuação compósita, de 1 a 10, é obtida pela média geométrica da pontuação individual das quatro áreas referidas:

Pontuação compósita $=\sqrt[4]{\text { Residuos } \times \text { Ambiente } \times \text { Saúde } \times \text { Segurança }}$

Esta pontuação compósita, combinada com as pontuações de quatro categorias consideradas prioritárias com base nas atividades da GSK (Emissões VOC, Perigo para a saúde, Inflamabilidade e Potencial de explosão, e Reatividade e Estabilidade, ver Tabela 2), definem a cor a ser atribuída ao solvente (vermelha, amarela ou verde) por aplicação de uma "árvore de decisão" [19]. As cores e as pontuações permitem ordenar os solventes e estabelecer uma hierarquização global. Contudo, a pontuação compósita não substitui as pontuações individuais das categorias que lhe dão origem, que devem ser sempre consultadas, nomeadamente em comparações de solventes cuja pontuação compósita seja semelhante.

Na Figura 2 apresentam-se os resultados de avaliação dos compostos da Tabela 1, onde são indicadas as cores compósitas (segunda coluna), as pontuações de cada categoria e as respetivas cores, de acordo com os critérios na Figura 1; os solventes foram ordenados como em [19].
As cores compósitas na Figura 2 indicam que o diclorometano, pentano, hexano, éter dietílico, éter de petróleo e tetracloreto de carbono são solventes de baixa verdura (vermelho), sendo de evitar, enquanto que o butan-1-ol, propan-1-ol, etanol, e propan-2-ol são relativamente benignos, sendo a sua utilização aceitável. O xileno, acetona e metanol apresentam verdura intermédia (amarelo).

\section{Ferramenta SHE}

Esta ferramenta tem por objetivo prospetar e sumariar de forma gráfica os perigos SHE de reagentes (ou de atividades laboratoriais que os utilizam) [20]. Em contraste com os guias de solventes, este objetivo não inclui a hierarquização das substâncias pela sua perigosidade. A ferramenta usa como base de informação as fichas de dados de segurança de produtos químicos (SDS), estabelecidas segundo a legislação vigente sobre a sua comunicação no quadro do Sistema Global Harmonizado de Classificação e Rotulagem de Produtos Químicos (GHS) [42,43] que classifica as substâncias e misturas de acordo com os seus perigos intrínsecos [44].

Para a aplicação da ferramenta SHE começa por consultar-se as SDS dos compostos a analisar, as quais podem ser obtidas nas páginas web de fornecedores de produtos químicos para laboratório [45,46]. Das SDS recolhe-se, para cada substância, informação acerca dos perigos SHE, através das respetivas advertências de perigo. As advertências de perigo, sinalizadas com um código de perigo (composto pela letra $\mathrm{H}$ ou EUH seguido de três algarismos [44]), são usadas para pontuar a perigosidade, de 0 (benignidade máxima) a 2 (perigosidade máxima), conforme se mostra na Figura 3, onde as diferentes categorias de perigos SHE são apresentadas com diferentes cores de fundo.

Para a definição das pontuações correspondentes às advertências de perigo de cada uma das três categorias foram definidos critérios tendo em vista o objetivo e a exequibili-

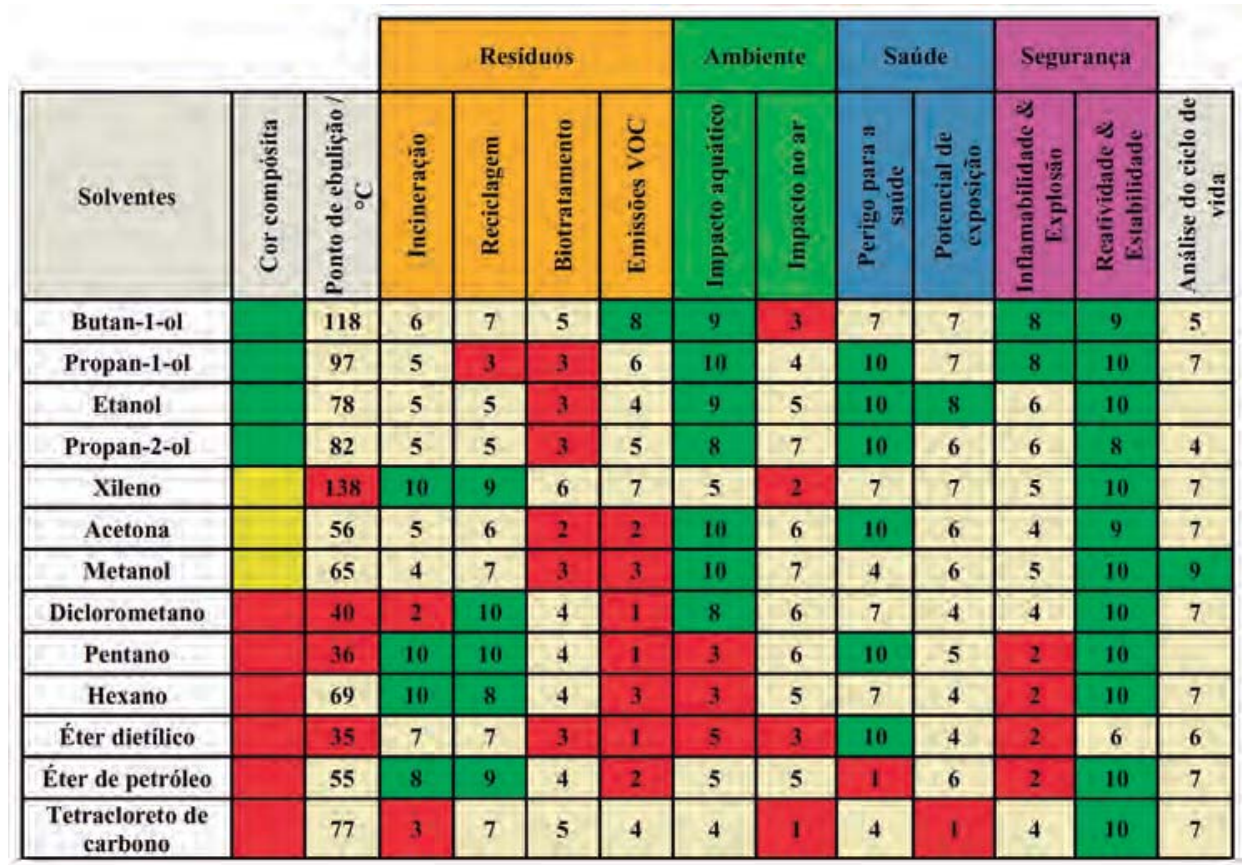

Figura 2 - Resultados do guia da GSK [19]; escala de 0 a 10 - solvente tanto mais benigno quanto maior for a pontuação; VOC - Volatile Organic Compound; cores compósitas, na segunda coluna. 


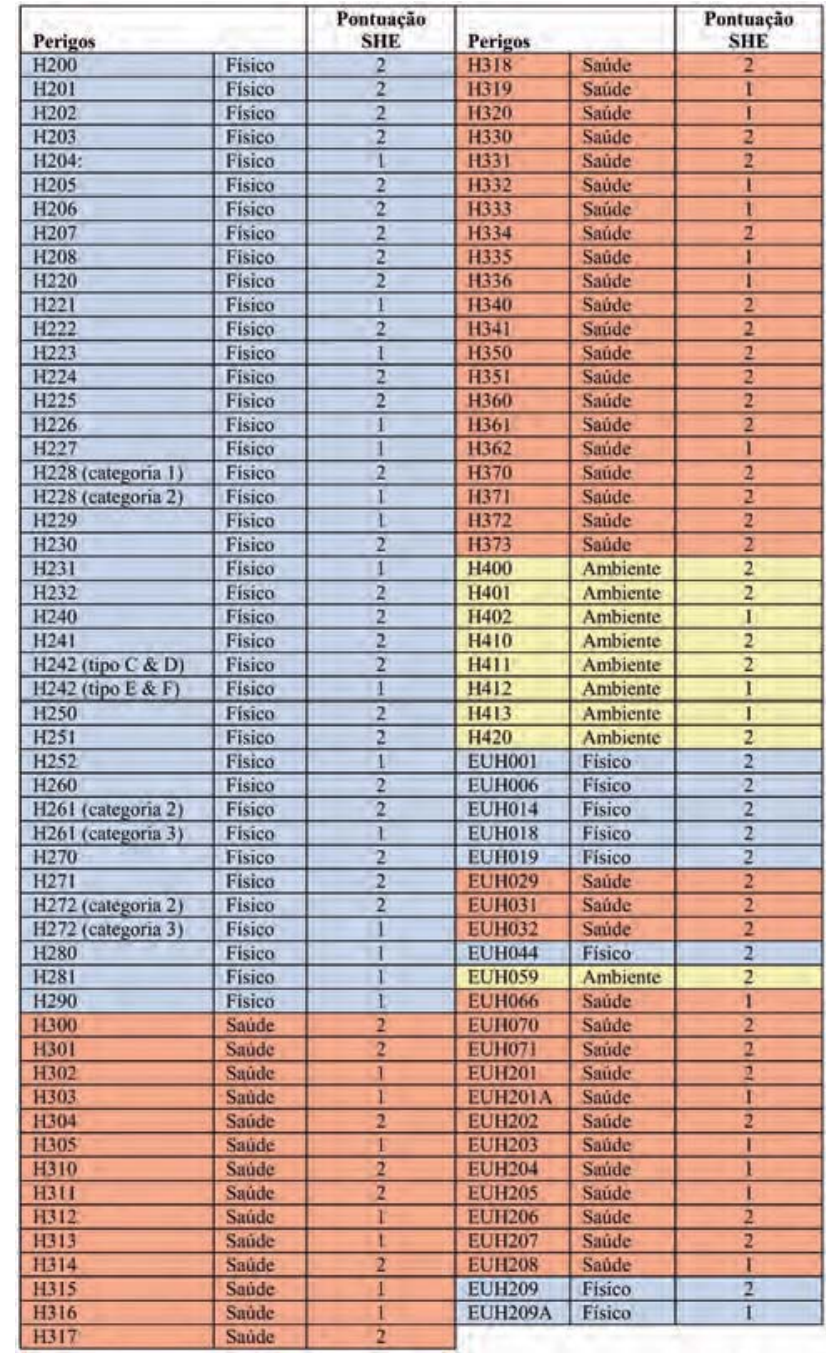

Figura 3 - Pontuações para classificar os perigos das substâncias na ferramenta SHE. dade de utilização, semelhantes aos utilizados na construção da estrela verde $[44,47,48]$. Quando a advertência de perigo é sinalizada com a palavra sinal “perigo” [44] é atribuída a pontuação 2 e quando é sinalizada com a palavra sinal "atenção" a pontuação é, como regra geral, 1. Contudo, há advertências com palavra sinal “atenção” a que foi atribuída a pontuação 2, apresentadas na Tabela 3 com as justificações. Em [49] pode obter-se um ficheiro Excel com todas as advertências de perigos e respetivos códigos, palavras sinal e pictogramas usados na ferramenta SHE.

Com base no conjunto das pontuações individuais das advertências de perigo de cada categoria, atribui-se a cada uma destas como pontuação final a respetiva pontuação máxima. Estas três pontuações máximas das advertências de perigos físicos $(\mathrm{S})$, para a saúde humana $(\mathrm{H})$ e para o ambiente (E) são usadas para a construção, em Excel, de um gráfico radial triangular ("triângulo SHE”, TSHE). A pontuação de cada vértice do TSHE indica o nível para a perigosidade física (vértice $S$ ), para a saúde humana (vértice $\mathrm{H}$ ) e para o ambiente (vértice E). O TSHE sumariza graficamente a perigosidade global da substância. Paralelamente, para cada solvente, as pontuações das advertências de perigo são representadas num gráfico de barras (“espetro de perigos potenciais”, EPP). O EPP proporciona informação gráfica detalhada sobre os diversos perigos do composto.

Em suma, a ferramenta SHE permite transmitir a informação sobre a perigosidade de uma substância de forma compacta e facilmente apreensível por via visual. Além disso, evidencia as advertências de perigo e os EPP permitem identificar os perigos envolvidos, fazendo sentir diretamente a perigosidade das substâncias. Assim, é útil para utilização em contexto escolar, porque proporciona de forma simples um leque de informação de segurança completa e detalhada a quem vai usar as substâncias, ou suporta

Tabela 3 - Pontuações de perigos que não seguem a regra geral.

\begin{tabular}{|c|c|}
\hline Expressões usadas nas advertências de perigo* & Código de perigo \\
\hline \multicolumn{2}{|l|}{ Saúde humana } \\
\hline “suspeito de provocar cancro” (atenção) & H351 \\
\hline “suspeito de afetar a fertilidade ou o nascituro” (atenção) & H361 \\
\hline “pode afetar órgãos específicos” (atenção) & H371, H373 \\
\hline "podem libertar gases perigosos" & EUH206 \\
\hline "liberta gases tóxicos" & EUH029, EUH031 \\
\hline "liberta gases muito tóxicos" & EUH032 \\
\hline “corrosivo para as vias respiratórias” & EUH071 \\
\hline "tóxico para os organismos aquáticos” & H411 \\
\hline “muito tóxico para os organismos aquáticos (atenção) & H410 \\
\hline “destrói o ozono na atmosfera superior” (atenção) & $\mathrm{H} 420$ \\
\hline \multicolumn{2}{|l|}{ Perigos físicos } \\
\hline “explosivo” & EUH001 \\
\hline “forma peróxidos explosivos, forma mistura vapor-ar explosiva” & EUH018, EUH019, \\
\hline “perigo de explosão” & EUH006, EUH044 \\
\hline "reage violentamente" & EUH014 \\
\hline “facilmente inflamável” & EUH209 \\
\hline
\end{tabular}


decisões sobre a escolha de substâncias a usar, solventes no presente caso.

\section{Análise da perigosidade dos solventes com a ferramenta SHE}

Os resultados da análise dos solventes da Tabela 1 com a ferramenta SHE são apresentados na Figura 4. Esta figura evidencia a eficácia desta ferramenta na sumarização dos perigos das substâncias, já que a sua inspeção visual proporciona, para cada substância: (i) a visualização global da pontuação máxima ( 0,1 ou 2) atribuída aos perigos de cada categoria SHE, através dos TSHE, que evidenciam a natureza multidimensional da informação; (ii) a identificação da natureza dos perigos envolvidos, através das advertências de perigos; (iii) a identificação do número e nível de perigos, pontuação atribuída de 0 a 2, através dos EPP; e (iv) a sinalização, a vermelho, dos códigos e advertências de perigo com pontuação máxima. A apresentação em conjunto destas informações tem a vantagem de permitir identificar, em paralelo, uma visão global do perigo máximo para cada categoria (TSHE), as categorias de perigo e respetivas pontuações (EPP), e as advertências de perigo, sendo realçadas a cor as de perigo elevado. A natureza gráfica da ferramenta SHE permite a aquisição da informação de modo visual e rapidamente, possibilitando uma perceção sumativa do nível de perigosidade da substância. Na referência [50] pode ser descarregado um ficheiro Excel que permite aplicar a ferramenta SHE a uma substância e obter automaticamente o seu resultado, em formato idêntico à Figura 4, bastando inserir o nome da substância e os respetivos códigos de perigo. Na referência [51] pode ser descarregada uma ficha de trabalho para o estudante efetuar manualmente a análise SHE de uma substância.

A análise da Figura 4 mostra que todos os solventes propostos nas atividades do Ensino Secundário apresentam pelo menos um perigo elevado (pontuação 2), mesmo quando se consideram apenas os perigos para a saúde e de perigosidade física, o que sugere que nenhum deles pode ser considerado totalmente seguro quanto a riscos para a integridade física dos estudantes.

No que se refere à saúde humana, nenhum dos solventes propostos é inócuo, mas a acetona, éter dietílico e propan-2-ol, apresentam perigos moderados (pontuação 1 para todas as advertências de perigo). É importante referir que os solventes mais perigosos apresentam perigos muito severos para a saúde humana, traduzidos por advertências de perigo graves: o tetracloreto de carbono e o diclorometano são suspeitos de provocar cancro (H351); e o éter de petróleo, hexano, pentano e xileno podem ser mortais por ingestão e penetração nas vias respiratórias (H304). O hexano é também suspeito de afetar a fertilidade (H361f). Quanto ao ambiente, só o xileno (pontuação 1) e o éter de petróleo, hexano e tetracloreto de carbono (com pontuação 2) apresentam perigos nesta categoria. Finalmente, no que se refere à perigosidade física os solventes butan-1-ol e xileno apresentam perigos moderados (pontuação 1) e os solventes diclorometano e tetracloreto de carbono não apresentam perigos; todos os outros apresentam perigos elevados por serem "facilmente ou extremamente inflamáveis” (H225 ou H224, respetivamente).

\section{Comparação das análises}

Nesta secção comparam-se os resultados globais obtidos com a ferramenta SHE com os do guia GSK. Para isso, atendendo a que na ferramenta SHE só são considerados os perigos SHE, apresentam-se na Figura 5 ambas as análises, com a do guia restringida a estes e indicando as pontuações resumo e as cores das categorias. Para a ferramenta SHE as cores foram atribuídas conforme as pontuações de perigo no EPP: vermelho, se ocorre pelo menos um perigo elevado (pontuação 2) para a categoria em análise; âmbar, se o perigo máximo é moderado (pontuação 1); e verde, se não ocorrem perigos (pontuação 0).

Em visão global, a Figura 5 mostra que na análise com a ferramenta SHE todos os solventes apresentam pelo menos uma categoria com perigos elevados (cor vermelha), o metanol e o tetracloreto de carbono apresentam duas e o pentano, hexano e éter do petróleo apresentam três. Com o guia GSK só os solventes xileno, éter dietílico, éter de petróleo e tetracloreto de carbono apresentam categorias com vermelho, uma para os três primeiros e duas para o último. Esta comparação sugere que, globalmente, a ferramenta SHE é mais exigente na avaliação da segurança que o guia GSK.

Uma análise mais detalhada da Figura 5 mostra que para o ambiente as duas análises apresentam concordância, em termos de perigo baixo (verde), para os solventes propan-2-ol, acetona e metanol; e, quanto a perigo elevado (vermelho), para o tetracloreto de carbono. Os solventes butan-1-ol, propan-1-ol, etanol, diclorometano e éter dietílico são pior avaliados pelo guia GSK (âmbar) do que pela ferramenta SHE (verde); bem como o xileno, vermelho pelo guia, mas âmbar pela ferramenta. Em contraste, os solventes pentano, hexano e éter de petróleo são melhor avaliados pelo guia (âmbar) do que pela ferramenta SHE (vermelho). Quanto à saúde, a concordância ocorre apenas para o éter dietílico (âmbar) e para o éter de petróleo e o tetracloreto de carbono (vermelho). Os solventes propan-1-ol, etanol, propan-2-ol e acetona apresentam perigo baixo (verde) pelo guia, mas moderado (âmbar) pela ferramenta SHE. Esta atribui aos solventes butan-1-ol, xileno, metanol, diclorometano, pentano e hexano perigo elevado (vermelho), enquanto que o guia lhes atribui perigo moderado (âmbar). Para a segurança/ perigosidade física há concordância entre as duas análises só para o xileno (âmbar) e éter dietílico (vermelho). $\mathrm{O}$ butan-1-ol, considerado de perigosidade baixa pelo guia, é aferido como de perigosidade moderada pela ferramenta SHE; seis solventes (propan-2-ol, acetona, metanol, pentano, hexano e éter do petróleo) são considerados de perigosidade intermédia pelo guia subindo para elevada na ferramenta SHE; o propan-1-ol e o etanol são considerados de perigosidade baixa pelo guia mas elevada pela ferramenta SHE, sendo os únicos casos em que ocorre um salto de verde para vermelho. Em contraste, para o tetracloreto de carbono e o diclorometano o guia aponta para perigosidade intermédia e a ferramenta para baixa. Esta comparação detalhada mostra que as diferenças nas avaliações não ocorrem sempre no mesmo sentido, embora na maioria dos casos a ferramenta SHE aponte para um nível de perigosidade superior. 


\begin{tabular}{|c|c|c|c|}
\hline Triângulos SHE (TSHE) & & Códigos e advertências de perigo & Espetros de perigos potenciais (EPP) \\
\hline \multicolumn{4}{|l|}{ Acetona } \\
\hline & H225 & Liquido e vapor facilmente inflamáveis & \multirow[t]{3}{*}{2} \\
\hline & H319 & Provoca irritação ocular grave & \\
\hline & $H 336$ & Pode provocar sonolência ou vertigens & \\
\hline \multicolumn{4}{|l|}{ Butan-1-ol } \\
\hline \multirow{6}{*}{$\int_{E}^{2}$} & $\mathrm{H} 226$ & Liquido e vapor inflamáveis & \multirow[t]{6}{*}{2} \\
\hline & $\mathrm{H} 302$ & Nocivo por ingestāo. & \\
\hline & $\mathrm{H} 315$ & Provoca irritação cutânea & \\
\hline & $\mathrm{H} 318$ & Provoca lesōes oculares graves & \\
\hline & H335 & Pode provocar irritação das vias respiratórias & \\
\hline & $\mathrm{H} 336$ & Pode provocar sonolência ou vertigens & \\
\hline \multicolumn{4}{|l|}{ Diclorometano } \\
\hline \multirow{6}{*}{ 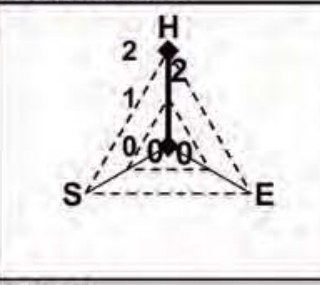 } & $\mathrm{H} 315$ & Provoca irritaçāo cutầnea & \multirow[t]{6}{*}{2} \\
\hline & $\mathrm{H} 319$ & Provoca irritação ocular grave & \\
\hline & $\mathrm{H} 335$ & Pode provocar irritação das vias respiratórias & \\
\hline & $\mathrm{H} 336$ & Pode provocar sonolềncia ou vertigens & \\
\hline & $\mathrm{H} 351$ & Suspeito de provocar cancro & \\
\hline & $\mathrm{H} 373$ & $\begin{array}{l}\begin{array}{l}\text { Pode afetar os órgăos (Figado, Sangue) após } \\
\text { exposiçāo prolongada ou repetida por } \\
\text { ingestâo }\end{array} \\
\end{array}$ & \\
\hline \multicolumn{4}{|c|}{ ( } \\
\hline & H225 & Liquido e vapor facilmente inflamáveis & \multirow{2}{*}{ 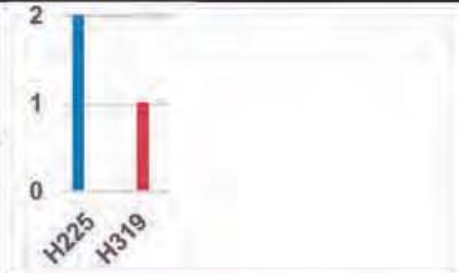 } \\
\hline & H319 & Provoca irritação ocular grave & \\
\hline \multicolumn{4}{|l|}{ Éter de petróleo } \\
\hline & $\mathrm{H} 224$ & Liquido e vapor extremamente inflamáveis & \multirow{7}{*}{ 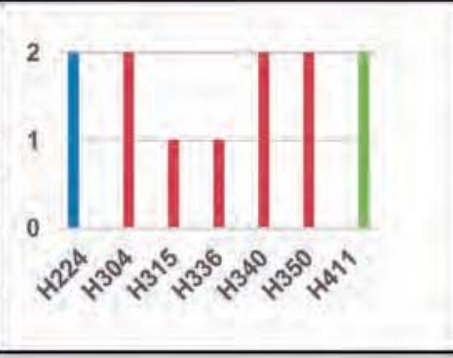 } \\
\hline & $\mathrm{H} 304$ & $\begin{array}{l}\text { Pode ser mortal por ingestão e penetração } \\
\text { nas vias respiratorias }\end{array}$ & \\
\hline & $\mathrm{H} 315$ & Provoca irritação cutânea & \\
\hline & $\mathrm{H} 336$ & Pode provocar sonolência ou vertigens & \\
\hline & $\mathrm{H} 340$ & Pode provocar anomalias genéticas. & \\
\hline & $\mathrm{H} 350$ & Pode provocar cancro. & \\
\hline & $\mathrm{H} 411$ & $\begin{array}{l}\text { Tóxico para os organismos aquáticos com } \\
\text { efeitos duradouros }\end{array}$ & \\
\hline \multicolumn{4}{|l|}{ Éter dietilico } \\
\hline \multirow{5}{*}{ (2) } & $\mathrm{H} 224$ & Liquido e vapor extremamente inflamáveis & \multirow{5}{*}{$\begin{array}{l}2 \\
1\end{array}$} \\
\hline & EUH019 & Pode formar peróxidos explosivos & \\
\hline & $\mathrm{H} 302$ & Nocivo por ingestão & \\
\hline & $\mathrm{H} 336$ & Pode provocar sonolência ou vertigens & \\
\hline & EUH066 & $\begin{array}{l}\text { Pode provocar pele seca ou gretada por } \\
\text { exposição repetida }\end{array}$ & \\
\hline \multicolumn{4}{|l|}{ Hexano } \\
\hline \multirow{7}{*}{ 2 } & $\mathrm{H} 225$ & Liquido e vapor facilmente inflamáveis & \multirow{7}{*}{1} \\
\hline & H304 & $\begin{array}{l}\text { Pode ser mortal por ingestāo e penetração } \\
\text { nas vias respiratórias }\end{array}$ & \\
\hline & $\mathrm{H} 315$ & Provoca irritação cutânea & \\
\hline & $\mathrm{H} 336$ & Pode provocar sonolência ou vertigens & \\
\hline & H361f & Suspeito de afetar a fertilidade & \\
\hline & $\mathrm{H} 373$ & $\begin{array}{l}\text { Pode afetar os órgāos após exposiçāo } \\
\text { prolongada ou repetida }\end{array}$ & \\
\hline & $\mathrm{H} 411$ & $\begin{array}{l}\text { Tóxico para os organismos aquáticos com } \\
\text { efeitos duradouros }\end{array}$ & \\
\hline
\end{tabular}

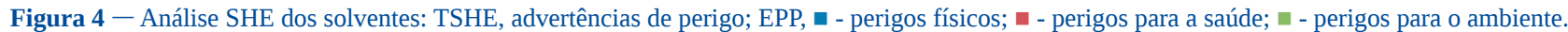




\begin{tabular}{|c|c|c|c|}
\hline Triângulos SHE (TSHE) & \multicolumn{2}{|c|}{ Códigos e advertências de perigo } & Espetros de perigos potenciais (EPP) \\
\hline \multicolumn{4}{|l|}{ Metanol } \\
\hline \multirow{5}{*}{${ }^{2}{ }_{0}^{\mathrm{H}}{ }^{2}$} & H225 & Liquido e vapor facilmente inflamáveis & \multirow[t]{5}{*}{2} \\
\hline & H301 & Tóxico por ingestão & \\
\hline & $\mathrm{H} 311$ & Tóxiço em contacto cóm a pele & \\
\hline & H331 & Tóxico por inalação & \\
\hline & $\mathrm{H} 370$ & Afeta os órgãos & \\
\hline \multicolumn{4}{|l|}{ Pentano } \\
\hline \multirow{5}{*}{$\underbrace{2}_{2}$} & $\mathrm{H} 225$ & Liquido e vapor facilmente inflamáveis & \multirow[t]{5}{*}{2} \\
\hline & $\mathrm{H} 304$ & $\begin{array}{l}\text { Pode ser mortal por ingestâo e penetraçāo } \\
\text { nas vias respiratorias }\end{array}$ & \\
\hline & $\mathrm{H} 336$ & Pode provocar sonolência ou vertigens. & \\
\hline & EUH066 & $\begin{array}{l}\text { Pode provocar pele seca ou gretada por } \\
\text { exposição repetida }\end{array}$ & \\
\hline & H411 & $\begin{array}{l}\text { Tóxico para os organismos aquáticos com } \\
\text { efeitos duradouros }\end{array}$ & \\
\hline \multicolumn{4}{|l|}{ Propan-1-ol } \\
\hline & H225 & Liquido e vapor facilmente inflamáveis & \multirow{3}{*}{$\left.\left.\left.\right|_{0} ^{2}\right|_{22^{5}} ^{23^{80}}\right|^{3^{30}}$} \\
\hline & H318 & Provoca lesőes oculares graves & \\
\hline 2 & H336 & Pode provocar sonolência ou vertigens & \\
\hline \multicolumn{4}{|l|}{ Propan-2-ol } \\
\hline & H225 & Liquido e vapor facilmente inflamáveis & \multirow{3}{*}{$\left.\left.\right|_{0} ^{2}\right|_{2^{5}} ^{23^{1^{9}}} x^{3^{60}}$} \\
\hline & H319 & Provoca irritação ocular grave & \\
\hline & H336 & Pode provocar sonolência ou vertigens & \\
\hline \multicolumn{4}{|l|}{ Tetracloreto de carbono } \\
\hline \multirow{7}{*}{2} & $\frac{\mathrm{H} 301}{\mathrm{H} 311}$ & Tóxico por ingestâo & \\
\hline & $\mathrm{H} 331$ & \begin{tabular}{|l|l|} 
Tóxico por inalaçăo \\
\end{tabular} & \\
\hline & $\mathrm{H} 317$ & $\begin{array}{l}\begin{array}{l}\text { Pode provocar uma reação alérgica } \\
\text { cutânea }\end{array} \\
\end{array}$ & \\
\hline & H351 & Suspeito de provocar cancro & \\
\hline & H372 & \begin{tabular}{|l|l|}
$\begin{array}{l}\text { Afeta os órgāos após exposição } \\
\text { prolongada ou repetida }\end{array}$ \\
\end{tabular} & \\
\hline & $\mathrm{H} 412$ & $\begin{array}{l}\text { Nocivo para os organismos aquáticos com } \\
\text { efeitos duradouros }\end{array}$ & \\
\hline & $\mathrm{H} 420$ & $\begin{array}{l}\text { Prejudica a saúde pública e o ambiente ao } \\
\text { destruir o ozono na atmosfera superior }\end{array}$ & \\
\hline \multicolumn{4}{|c|}{ 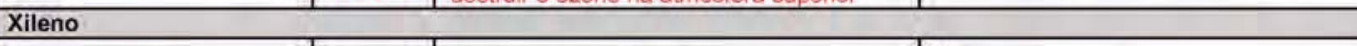 } \\
\hline \multirow{4}{*}{ 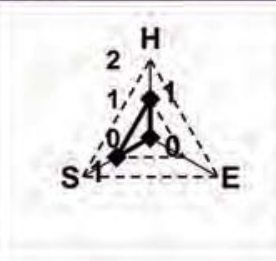 } & H226 & Liquido e vapor inflamáveis & \multirow{4}{*}{$\left.\left.\right|_{0} ^{1}\right|_{2^{2}+3^{2}+3^{5}+3^{32}} ^{2}$} \\
\hline & H312 & Nocivo em contacto com a pele & \\
\hline & H315 & Provoca irritaçắo cutânea & \\
\hline & H332 & Nocivo por inalação & \\
\hline
\end{tabular}

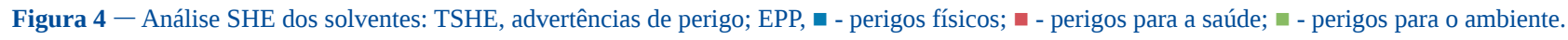
(continuação)

Os resultados díspares são esperados atendendo a que os critérios usados nas duas análises são distintos, consequência das diferentes conceções, interesses e objetivos que estiveram na base da sua conceção. Nomeadamente, como os critérios usados na construção da ferramenta SHE se baseiam unicamente na classificação dos perigos baseada no sistema GHS e a escala de pontuação é restrita de 0 a 2, a discriminação entre os perigos é limitada. Por exem- plo, na ferramenta SHE os perigos H224 (vapor extremamente inflamável) e H225 (vapor facilmente inflamável) têm a mesma pontuação (2), o que implica que o etanol e o éter dietílico apresentem a mesma pontuação (máxi$\mathrm{ma}$ ) na categoria de perigos físicos. Em contraste, o guia GSK envolve uma elevada sofisticação na análise a partir de dados de natureza diversa e inclui a avaliação de um número elevado de parâmetros (6 para o ambiente, 3 para 


\begin{tabular}{|l|c|c|c|c|c|c|}
\hline \multirow{2}{*}{ Solventes } & \multicolumn{2}{|c|}{ Ambiente } & \multicolumn{2}{c|}{ Saúde } & \multicolumn{2}{c|}{$\begin{array}{c}\text { Segurança ou } \\
\text { perigosidade física }\end{array}$} \\
\cline { 2 - 7 } & GSK & SHE & GSK & SHE & GSK & SHE \\
\hline Butan-1-ol & $\mathbf{5 , 2}$ & 0 & 7,0 & 2 & 8,5 & 1 \\
\hline Propan-1-ol & $\mathbf{6 , 3}$ & 0 & 8,4 & 1 & 8,9 & 2 \\
\hline Etanol & 6,7 & 0 & 8,9 & 1 & 7,7 & 2 \\
\hline Propan-2-ol & 7,5 & 0 & 7,7 & 1 & 6,9 & 2 \\
\hline Xileno & 3,2 & 1 & 7,0 & 2 & 7,1 & 1 \\
\hline Acetona & 7,7 & 0 & 7,7 & 1 & 6,0 & 2 \\
\hline Metanol & 8,4 & 0 & 4,9 & 2 & 7,1 & 2 \\
\hline Diclorometano & 6,9 & 0 & 5,3 & 2 & 6,3 & 0 \\
\hline Pentano & 4,2 & 2 & 7,1 & 2 & 4,5 & 2 \\
\hline Hexano & 3,9 & 2 & 5,3 & 2 & 4,5 & 2 \\
\hline Éter dietilico & 3,9 & 0 & 6,3 & 1 & 3,5 & 2 \\
\hline Éter de petróleo & $\mathbf{5 , 0}$ & 2 & 2,4 & 2 & 4,5 & 2 \\
\hline Tetracloreto de carbono & 2,0 & 2 & 2,0 & 2 & 6,3 & 0 \\
\hline
\end{tabular}

Figura 5 - Resultados globais do guia GSK e da ferramenta SHE. Pontuações: guia GSK, 1-10; ferramenta SHE, 0-2; as pontuações são diferentes já que obedecem a critérios diferentes, pontuação mais alta no guia GSK é indicação de menor perigosidade e na ferramenta SHE, o inverso.

a saúde e 10 para a segurança), que permite uma escala de pontuação mais fina, de 1 a 10 , embora de sentido inverso. No entanto, em consequência da exigência de um maior conjunto de dados, a sua aplicação restringe-se a um conjunto restrito de solventes, não sendo também extensível a outras substâncias.

Em suma, a ferramenta SHE mostrou-se mais severa para a caraterização da segurança dos solventes que o guia GSK, possibilitando uma perspetiva mais securitária. Considerando que no Ensino Secundário é usado o sistema GHS, nomeadamente nas SDS e rótulos das embalagens, e também que uma perspetiva mais exigente potencia maior atenção à segurança e formação da comunidade educativa neste campo, a maior severidade da ferramenta SHE tem vantagens para tornar os laboratórios escolares mais seguros e reduzir o risco de acidentes e exposições nocivas a substâncias químicas.

\section{Discussão}

A seguir discute-se as principais implicações do presente estudo quanto à utilização dos solventes e outros aspetos da segurança laboratorial no Ensino Secundário.

\section{Solventes perigosos}

O presente estudo evidencia o problema da segurança dos solventes orgânicos "tradicionais”, por exemplo, mesmo o etanol, apesar de o seu uso laboratorial não apresentar perigos para a saúde humana, exige cuidado no seu manuseamento dado os elevados perigos físicos. No ensino da química, em especial nos anos iniciais, quando os estudantes experimentam o seu primeiro contato com o laboratório, é aconselhável usar reagentes com poucos perigos, nomeadamente quanto a saúde e perigosidade física, para evitar acidentes e exposições que ponham em causa a sua saúde (embora os aspetos ambientais tenham também de ser considerados para o tratamento de resíduos, ver a seguir).

O estudo mostra que vários solventes sugeridos em trabalhos de laboratório incluídos nos programas do Ensino Secundário de Física e Química envolvem elevada perigo- sidade e que alguns manuais propõem a sua substituição por outros igualmente perigosos. Por exemplo, os solventes diclorometano, éter dietílico, pentano, hexano, metanol e xileno não são indicados no programa para o $10 .^{\circ}$ ano, mas sim sugeridos em manuais escolares, sendo os quatro primeiros considerados muito perigosos no guia GSK e todos eles muito perigosos na análise com a ferramenta SHE.

Por outro lado, cinco dos solventes propostos apresentam indicações de perigo para o ambiente: pentano, xileno, hexano, éter de petróleo e tetracloreto de carbono. A sua utilização implica uma gestão cuidada dos resíduos no laboratório, que se torna mais complexa quando envolve maior variedade de solventes diversificados. Além disso, o tratamento de resíduos laboratoriais nas escolas secundárias é frequentemente problemático, também porque é dispendioso enviar resíduos perigosos para centros de tratamento.

Em suma, os resultados deste trabalho sugerem que os responsáveis pelos programas devem realizar uma análise cuidadosa da perigosidade dos solventes propostos nas atividades para o Ensino Secundário, o que passa por prestarem atenção proativa na escolha das experiências a realizar. A mesma sugestão é deixada aos autores de manuais quando propõem o uso de solventes nas experiências. Claro que esta postura cautelar deve também ser extrapolada para as demais substâncias usadas nas experiências. Se for decidido manter uma atividade com reagentes que envolvam perigos elevados, deve ser considerada a substituição destes por outros mais benignos; se não for possível, pode realizar-se a atividade em microescala $[52,53]$ mas alertando os estudantes para a perigosidade dos reagentes usados.

\section{Limitações dos programas quanto a segurança laboratorial}

Os programas atuais do Ensino Secundário prescrevem que os perigos dos reagentes sejam avaliados a partir da informação fornecida nos rótulos dos reagentes (nos programas lê-se: "Deve ser feita a análise dos rótulos de reagentes para que sejam identificados riscos associados à manipulação dos reagentes e medidas de segurança 
adequadas", [21] pág. 30, e "Interpretar informação de segurança nos rótulos de reagentes e adotar medidas de proteção com base nessa informação e em instruções recebidas”, [21] pág. 77. Em face da atenção crescente dada à segurança química e do aumento da quantidade de informação que, na esteira do REACH e do GHS, vem sendo disponibilizada nas SDS, será preferível prescrever a consulta destas para obter informação de segurança, já que são o instrumento fundamental para a transmissão do conhecimento sobre o perigo das substâncias e misturas. Sem pôr em causa a leitura dos rótulos, apontam-se aqui limitações da sua prescrição: como a informação a fornecer é cada vez mais longa, o tamanho da letra das informações nos rótulos tende a diminuir, tornando difícil a leitura das advertências de perigo; os rótulos podem ser antigos, não correspondendo à legislação vigente e omitindo informação recente; além disso, podem estar danificados e serem em parte ilegíveis.

\section{Suporte à pedagogia da segurança}

Atendendo à importância crescente da segurança na prática da química, será útil para a formação dos estudantes que eles sejam treinados na análise dos perigos dos reagentes envolvidos nas atividades laboratoriais antes de as realizarem, com base na consulta das SDS respetivas. Como a ferramenta SHE implica pontuar as advertências de perigo contidas nas SDS, a sua aplicação aos reagentes, antes das atividades laboratoriais, permite que os estudantes tomem contacto com as especificidades das advertências de perigo e aumentem os seus conhecimentos sobre a perigosidade química. Mesmo aos níveis mais elementares, como os resultados da ferramenta SHE são apresentados numa representação gráfica que facilita a identificação do grau de perigosidade do composto por mera inspeção visual, podem ser usados gráficos obtidos pelo professor para mostrar aos estudantes os perigos dos reagentes usados em cada experiência, e da atividade laboratorial no seu conjunto, permitindo-lhes tomar mais precocemente consciência da importância da segurança. No entanto, é importante notar que a segurança no laboratório envolve outros componentes além dos perigos das substâncias, nomeadamente a interação entre os reagentes nas reações químicas a realizar, bem como em reações imprevistas, causadores de acidentes graves em laboratórios. Este aspeto deve ser considerado também no armazenamento. Para consideração de problemas decorrentes da reatividade, podem consultar-se tabelas de incompatibilidades entre reagentes (tabelas deste tipo são acessíveis na ref. [54]).

Quanto à utilização de guias de seleção de solventes no ensino, como a sua construção se baseia em tratamento de dados por processos ocultos para o utilizador para a atribuição de pontuações em diversas categorias de perigos, quando estas parecem suspeitas não há processo de esclarecer como foram obtidas, o que torna menos pedagógico o seu uso. No entanto, o guia atual da GSK [19] é apresentado com informação detalhada sobre o modo como foram estabelecidas as pontuações, o que permite avaliar certas situações duvidosas. Em consequência, pode ser útil no ensino superior por apresentar informação sistematizada de aspetos que podem ser abordados para discussão mais aprofundada, já que o guia faz uma avaliação mais ampla da verdura dos solventes, considerando outras categorias de análise para além das utilizadas na ferramenta SHE.

\section{Conclusões}

O presente estudo evidencia que alguns dos solventes propostos nos programas do Ensino Secundário envolvem riscos de manuseamento elevados e não são adequados para integrar o ensino laboratorial da Química a este nível - devem ser banidos do laboratório, também porque nem sempre existem as condições necessárias quer para o manuseamento de reagentes perigosos com segurança, quer para a eliminação adequada de resíduos perigosos.

Mais amplamente, a promoção da segurança nos laboratórios do Ensino Secundário deve ser conseguida com programas e manuais escolares com propostas que envolvam reagentes benignos e experiências seguras, não esquecendo a utilização de instrumentos que permitam aferir o grau de benignidade dos reagentes e a segurança das atividades propostas. A ferramenta SHE, de construção fácil e que proporciona resultados gráficos de apreensão imediata, mostrou-se apropriada para este fim.

O ensino da Química deve seguir o paradigma ecológico, sobre o qual a QV assenta, e visar a eliminação da perigosidade intrínseca no laboratório, seja quanto a solventes ou quaisquer outros reagentes. Para isso, é importante a introdução no laboratório de uma componente pedagógica dirigida à segurança proativa baseada na $\mathrm{QV}$, particularmente útil a nível universitário. Neste contexto, o uso da ferramenta SHE proporciona aos estudantes oportunidade de lidar com informação variada sobre os perigos das substâncias químicas, contribuindo para o aumento da sua cultura de segurança.

\section{Agradecimentos}

O trabalho de MGTCR e JRMP recebeu apoio financeiro da União Europeia (fundos FEDER POCI/01/0145/FEDER/007265) e de fundos nacionais (FCT, Fundação para a Ciência e a Tecnologia) no âmbito do Acordo de Parceria PT2020 UID/QUI/50006/2013.

\section{Referências}

[1] A.A.S.C. Machado, Quim. Nova 34 (2011) 535-543.

[2] P.T. Anastas, J.C. Warner, "Green Chemistry: Theory and Practice", Oxford University Press, 1998.

[3] A.A.S.C. Machado, Revista Brasileira de Ensino da Química 11 (2016) 93-108.

[4] A.A.S.C. Machado, As potencialidades da Química Verde para o ensino da Segurança Laboratorial, Conferência Plenária, XVIII Encontro Nacional de Ensino de Química (ENEQ XVIII), Brasil, 2016

[5] D. Prat, J. Hayler, A. Wells, Green Chem. 16 (2014) 45464551.

[6] D.J.C. Constable, P.J. Dunn, J.D. Hayler, G.R. Humphrey, J.J.L. Leazer, R.J. Linderman, K. Lorenz, J. Manley, B.A. Pearlman, A. Wells, A. Zaks, T.Y. Zhang, Green Chem. 9 (2007) 411-420.

[7] ACS GCI Pharmaceutical Roundtable: http://www.acs.org/ gcipharmaroundtable (acedido em 12-07-2017).

[8] L.C. McKenzie, L.M. Huffman, J.E. Hutchison, C.E. Rogers, T.E. Goodwin, G.O. Spessard, J. Chem. Educ. 86 (2009) 488-493. 
[9] E. Aktoudianakis, E. Chan, A.R. Edward, I. Jarosz, V. Lee, L. Mui, S.S. Thatipamala, A.P. Dicks, J. Chem. Educ. 86 (2009) 730-732.

[10] A.P. Dicks, Green Chem. Lett. Rev. 2 (2009) 87-100.

[11] A.P. Dicks, Green Chem. Lett. Rev. 2 (2009) 9-21.

[12] A. Hampp, J. Chem. Educ. 73 (1996) 1172.

[13] L. Hie, J.J. Chang, N.K. Garg, J. Chem. Educ. 92 (2015) 571-574.

[14] S.C. Petrovic, G.M. Bodner, J. Chem. Educ. 68 (1991) 509.

[15] J.P. Williams, K.J. West, K.L. Erickson, J. Chem. Educ. 69 (1992) 669-670.

[16] U.S. Chemical Safety Board, Flammable Chemicals in Educational Demontrations: http://www.csb.gov/csb-releases-key-lessons-for-preventing-incidents-from-flammable-chemicals-in-educational-demonstrations-in-wake-ofseveral-serious-methanol-accidents-that-injured-childrenand-adults/ (acedido em 12-07-2017).

[17] H.J. Elston, J. Chem. Health Safety 24 (2017) 1.

[18] C.R. Bertozzi, ACS Central Science 2 (2016) 764-766.

[19] C.M. Alder, J.D. Hayler, R.K. Henderson, A.M. Redman, L. Shukla, L.E. Shuster, H.F. Sneddon, Green Chem. 18 (2016) 3879-3890.

[20] A.P. Serra. Ferramentas para Avaliação SHE de Atividades Laboratoriais para o Ensino Secundário. Tese de Mestrado, Faculdade de Ciências, Universidade do Porto, 2015.

[21] DGE - Programa e Metas Curriculares de Física e Química A:http://www.dge.mec.pt/sites/default/files/Secundario /Documentos/Documentos_Disciplinas_novo/Curso_ Ciencias_Tecnologias/Fisica_Quimica_A/programa_ fqa_10_11.pdf (acedido em 12-07-2017).

[22] C. Rodrigues, C. Santos, L. Miguelote, P. Santos, "Química 10 A", Areal Editores, Porto, 2015.

[23] A. Amaro, P. Ferreira, "Química 10 - Física e Química A 10. ${ }^{\circ}$ Ano", Raíz Editores, Lisboa, 2015.

[24] C. Cunha, C.C. Silva, M. Vieira, "Eu e a Química A 10 Caderno do Professor", Porto Editora, Porto, 2015.

[25] M.A. Queirós, M.O. Simões, T.S. Simões, "Há Química entre Nós 10 - Química A", Porto Editora, Porto, 2015.

[26] A.J. Ferreira, C. Fiolhais, J. Paiva, "Novo 10 Q - Química A 10. ${ }^{\circ}$ Ano", Texto Editores, Lisboa, 2015.

[27] A. Marques, F. Coelho, F. Soares, "Química entre nós $10{ }^{\circ}$ ano", Santillana, Barcarena, 2015.

[28] DGE - Metas Curriculares de Química: http://www.dge. mec.pt/sites/default/files/Secundario/Documentos/Documentos_Disciplinas_novo/Curso_Ciencias_Tecnologias/ Quimica/metas_curriculares_quimica_12.pdf (acedido em 12-07-2017).

[29] M.C. Dantas, M.D. Ramalho, "Novo Jogo Partículas A Química A 10. ${ }^{\circ}$ Ano, Caderno de Atividades Laboratoriais", Texto Editores, Lisboa, 2015.

[30] L.J. Diorazio, D.R.J. Hose, N.K. Adlington, Org. Process Res. Dev. 20 (2016) 760-773.

[31] K. Alfonsi, J. Colberg, P.J. Dunn, T. Fevig, S. Jennings, T.A. Johnson, H.P. Kleine, C. Knight, M.A. Nagy, D.A. Perry, M. Stefaniak, Green Chem. 10 (2008) 31-36.

[32] A.D. Curzons, D.C. Constable, V.L. Cunningham, Clean Technol. Environ. Policy 1 (1999) 82-90.
[33] C. Jiménez-González, A.D. Curzons, D.J.C. Constable, V.L. Cunningham, Int. J. Life Cycle Ass. 9 (2005) 114121.

[34] R.K. Henderson, C. Jimenez-Gonzalez, D.J.C. Constable, S.R. Alston, G.G.A. Inglis, G. Fisher, J. Sherwood, S.P. Binks, A.D. Curzons, Green Chem. 13 (2011) 854-862.

[35] D. Prat, O. Pardigon, H.-W. Flemming, S. Letestu, V. Ducandas, P. Isnard, E. Guntrum, T. Senac, S. Ruisseau, P. Cruciani, P. Hosek, Org. Process Res. Dev. 17 (2013) 1517-1525.

[36] ACS GCI Pharmaceutical Roundtable - Collaboration to Deliver a Solvent Selection Guide for the Pharmaceutical Industry: https://www.acs.org/content/dam/acsorg/greenchemistry/industriainnovation/roundtable/solvent-selection-guide.pdf (acedido em 12-07-2017).

[37] ACS GCI Pharmaceutical Roundtable Solvent Selection Guide (Version 2.0): https://www.acs.org/content/ dam/acsorg/greenchemistry/industriainnovation/roundtable/acs-gci-pr-solvent-selection-guide.pdf (acedido em 12-07-2017).

[38] https://www.chem21.eu/ (acedido em 12-07-2017).

[39] G. Koller, U. Fischer, K. Hungerbühler, Ind. Eng. Chem. Res. 39 (2000) 960-972.

[40] D. Prat, A. Wells, J. Hayler, H. Sneddon, C.R. McElroy, S. Abou-Shehada, P.J. Dunn, Green Chem. 18 (2016) 288$-296$.

[41] J.R.M. Pinto. Avaliação da Utilização dos Solventes na Síntese Laboratorial numa Perspetiva da Química Verde (em preparação). Tese de Doutoramento. Faculdade de Ciências, Universidade do Porto.

[42] http://eur-lex.europa.eu/legal-content/PT/TXT/PDF/?ur $\mathrm{i}=$ CELEX:32008R1272\&from=PT (acedido em 12-07-2017).

[43] http://www.unece.org/trans/danger/publi/ghs/ghs_ rev05/05files_e.html (acedido em 12-07-2017).

[44] M.G.T.C. Ribeiro, S.F. Yunes, A.A.S.C. Machado, J. Chem. Educ. 91 (2014) 1901-1908.

[45] http://www.sigmaaldrich.com/ (acedido em 12-07-2017).

[46] http://www.merckmillipore.com/ (acedido em 12-07-2017).

[47] D.A. Costa, M.G.T.C. Ribeiro, A.A.S.C. Machado, Química - Bol. SPQ n. ${ }^{\circ} 115$ (2009) 41-49.

[48] D.A. Costa, M.G.T.C. Ribeiro, A.A.S.C. Machado, Química - Bol. SPQ n. ${ }^{\circ} 123$ (2011) 63-74.

[49] http://educa.fc.up.pt/documentosQV/Perigos_GHS_ PT.xlsx (acedido em 12-07-2017).

[50] http://educa.fc.up.pt/documentosSHE/ferramenta_SHE_ substancias.xlsx (acedido em 12-07-2017).

[51] http://educa.fc.up.pt/documentosSHE/ficha_construcao_ SHE_estudantes.pdf (acedido em 12-07-2017).

[52] M.M. Singh, Z. Szafran, R.M. Pike, J. Chem. Educ. 76 (1999) 1684-1686.

[53] Z. Szafran, M.M. Singh, R.M. Pike, Educación Química 11 (2000) 172-173.

[54] http://www.merckmillipore.com/PT/en/support/safety/ safe-storage/oaSb.qB.i0MAAAFCzrkXr74v,nav (acedido em 12-07-2017). 